\title{
Androgen-independent prostate cancer cells circumvent EGFR inhibition by overexpression of alternative HER receptors and ligands
}

\author{
DOLORS CARRIÓN-SALIP ${ }^{1}$, CLARA PANOSA ${ }^{1}$, JAVIER A. MENENDEZ ${ }^{2}$, TERESA PUIG ${ }^{3}$, \\ GLÒRIA OLIVERAS $^{3}$, ATANASIO PANDIELLA ${ }^{4}$, RAFAEL DE LLORENS ${ }^{1}$ and ANNA MASSAGUER ${ }^{1}$ \\ ${ }^{1}$ Biochemistry and Molecular Biology Unit, Department of Biology, University of Girona, Girona 17071; \\ ${ }^{2}$ Unit of Translational Research, Catalan Institute of Oncology-Girona, Dr Josep Trueta University Hospital, Girona 17007; \\ ${ }^{3}$ Department of Medical Science, Girona Institute for Biomedical Research, University of Girona, Girona 17071, Catalonia; \\ ${ }^{4}$ Institute of Molecular and Cellular Biology of Cancer, University of Salamanca, Salamanca 37007, Spain
}

Received March 1, 2012; Accepted May 4, 2012

DOI: 10.3892/ijo.2012.1509

\begin{abstract}
The deregulation of the epidermal growth factor receptor (EGFR) pathway plays a major role in the pathogenesis of prostate cancer (PCa). However, therapies targeting EGFR have demonstrated limited effectiveness in $\mathrm{PCa}$. A potential mechanism to overcome EGFR blockade in cancer cells is the autocrine activation of alternative receptors of the human EGFR (HER) family through the overexpression of the HER receptors and ligands. In the present study, we were interested in analyzing if this intrinsic resistance mechanism might contribute to the inefficacy of EGFR inhibitors in PCa. To this end, we selected two androgen-independent human prostate carcinoma cell lines (DU145 and PC3) and established DU145 erlotinib-resistant cells (DUErR). Cells were treated with three EGFR inhibitors (cetuximab, gefinitib and erlotinib) and the sensitivity to each treatment was assessed. The gene expression of the four EGFR/HER receptors and seven ligands of the HER family was analyzed by real-time PCR prior to and after each treatment. The receptors expression and activation were further characterized by flow cytometry and western blot analysis. EGFR inhibition rapidly induced enhanced gene expression of the EGF, betacellulin and neuregulin-1 ligands along with HER2, HER3 and HER4 receptors in the DU145 cells. In contrast, slight changes were observed in the PC3 cells, which are defective in the phosphatase and tensin homolog (PTEN) tumor suppressor gene. In the erlotinib-resistant DUErR cells, the expression of HER2 and HER3 was increased at mRNA and protein levels together with neuregulin-1, leading to enhanced
\end{abstract}

Correspondence to: Dr Anna Massaguer, Biochemistry and Molecular Biology Unit, Department of Biology, University of Girona, Campus Montilivi, Girona 17071, Catalonia, Spain

E-mail: anna.massaguer@udg.edu

Key words: prostate cancer, epidermal growth factor receptor, human epidermal growth factor receptor 3, neuregulin, erlotinib, resistance
HER3 phosphorylation and the activation of the downstream PI3K/Akt survival pathway. HER3 blockage by a monoclonal antibody restored the cytostatic activity of erlotinib in DUErR cells. Our results confirm that the overexpression and autocrine activation of HER3 play a key role in mediating the resistance to EGFR inhibitors in androgen-independent PCa cells.

\section{Introduction}

The growth and function of a normal prostate is mainly controlled via endocrine and paracrine factors. In this context, androgens play a major role by regulating the expression of specific genes to maintain the prostate homeostasis (1). When a prostate cancer (PCa) develops, the majority of the tumors remain initially androgen-dependent and thus, the first-line treatment of PCa is based on androgen ablation. However, in many cases the tumor cells progress to a hormone refractory state, generating androgenindependent tumors with increased proliferation and invasion capacity. In this situation, the therapeutic options are limited and the prognosis is poor (2). The proliferation of the androgen-independent PCa cells is mediated principally by autocrine factors, such as the epidermal growth factor and their receptors, which may interact with the androgen receptor in absence of androgen ligand binding, constituting an essential signaling pathway for tumor growth, invasion and metastasis $(3,4)$.

The human epidermal growth factor receptor (HER) family includes four type 1 transmembrane receptors: EGFR, HER2 (ErbB2), HER3 (ErbB3) and HER4 (ErbB4). They consist of a large extracellular ligand-binding region, a transmembrane segment and an intracellular tyrosine kinase domain. Stimulation through ligand binding induces the homodimerization or heterodimerization of a receptor with another family member at the plasma membrane, resulting in the phosphorylation of specific tyrosine residues in their cytoplasmic tail that leads to the activation of several signaling cascades, predominantly the ERK1/2 and the phosphatidylinositol 3-kinase (PI3K)/Akt pathways (5). These pathways control multiple biological processes like cellular proliferation, differentiation, survival, migration, and angiogenesis (6). Of the four receptors, HER2 and HER3 
are dependent proteins: the HER2 extracellular domain lacks ligand-binding capacity, while HER3 has a very weak kinase activity (7). However, HER2-HER3 heterodimers are highly functional and constitute the most active signaling dimer in this family. These receptors are activated by a number of ligands that are EGF-related peptide growth factors. They are classified in three groups depending on their receptor binding specificity: epidermal growth factor (EGF), amphiregulin (AR), epigen, and transforming growth factor- $\alpha$ (TGF- $\alpha$ ) bind exclusively to EGFR; betacellulin (BTC), epiregulin (EPR) and heparinbinding EGF (HB-EGF) bind to EGFR and HER4; and the neuregulin (NRG1-4) family members, NRG1 and NRG2, bind to HER3 and HER4, whereas NRG3 and NRG4 bind exclusively to HER4 (8). Importantly, HER ligands diversify the pattern of receptor activation and can direct different biological responses, even when they bind to the same receptor (9). However, the HER ligands share a significant degree of functional redundancy, as HB-EGF is the only ligand whose absence results in postnatal lethality (10).

The HER family, especially EGFR and HER2, are frequently deregulated in cancer cells as a result of overexpression, mutations, or increased ligand production $(11,12)$. In general terms, their enhanced expression in the tumor correlates with a worse clinical outcome $(13,14)$. In the recent years, intense efforts have been focused on the development of therapeutic strategies to block EGFR and HER2 signaling. Two families of HER-directed agents have demonstrated clinical activity and are currently in use for the treatment of cancer: monoclonal antibodies (MAbs) directed against the extracellular domain of the receptors and small molecule tyrosine kinase inhibitors (TKIs) that bind to the ATP-binding site of the tyrosine kinase domain of the receptors (15-17). However, the marked differences in the specificity and clinical efficiency of the HER inhibitors in different carcinomas as well as the development of resistances have limited the efficacy of these drugs $(18,19)$. In PCa, EGFR, HER2 and HER3 expression levels are increased as the disease progresses from localized to metastasic and to the androgen-independent state and these receptors have long been implicated in the survival of androgen-independent prostate cancer cells (20-23). Thus, the HER family members have been considered as potential therapeutic targets in prostate cancer. However, despite the blockade of EGFR or HER2 having demonstrated an ability to inhibit the proliferation of human prostate tumor cells (24-26), the clinical results have revealed only slight benefit of the HER-targeted therapy in patients with androgen-independent PCa both when EGFR inhibitors were administered as monotherapy or in association with antiandrogens or chemotherapeutics (27-33). The molecular mechanism underlying the low efficiency of EGFR inhibitors in human PCa remains to be elucidated.

As tumor cells co-express several HER receptors and ligands (34), the blockade of a single HER receptor function can be compensated by the cell both increasing the expression of alternative HER receptors or upregulating the production of HER-ligands, establishing autocrine growth factor loops that maintain downstream signaling and cellular proliferation. In a previous study, we described the capacity of a subset of breast cancer cell lines to compensate for the loss of EGFR receptor function after gefitinib treatment by upregulating the expression of genes coding for EGF-related ligands, especially EPR, NRG and EGF (35). The changes in the expression pattern remarkably correlated with the intrinsic degree of sensitivity of the breast cancer cells to the antiproliferative effects of gefitinib. Similar findings were described for a cetuximab-resistant non-small cell lung cancer, which overexpressed HER family ligands, especially EGF, AR, HB-EGF and BTC (36), and for human breast cancer cells selected for resistance to trastuzumab, which presented an amplified ligand-induced activation of HER receptors (37). The overexpression of neuregulin has also been involved in the resistance of breast cancer cells to EGFR-TKIs $(38,39)$. In addition, emerging studies are demonstrating that the reactivation of HER3 is a prominent mechanism of resistance to the current TKIs targeting EGFR and HER2 (40-42).

In this work, we were interested in examining the capacity of androgen-independent PCa cells to modulate the expression of the HER family members as an intrinsic mechanism of resistance to EGFR-targeted therapies. To this end, we have analyzed the changes in the expression pattern of different HER receptors and ligands in two androgen-independent PCa cell lines in response to the treatment with the EGFR-directed antibody cetuximab and two EGFR TKIs, gefitinib and erlotinib. We have also established an erlonitib-resistant cell line in order to further determine the relevance of this molecular mechanism in the resistance of prostate cancer cells to EGFR TKIs.

\section{Materials and methods}

Reagents. Cetuximab (Erbitux ${ }^{\circledR}$, Merck-Serono, Darmstadt, Germany) and trastuzumab (Herceptin ${ }^{\circledR}$, Roche, Basel, Switzerland) were kindly provided by the pharmacy of the Catalan Institute of Oncology (Hospital Dr Josep Trueta, Girona, Spain). Erlotinib (Tarceva ${ }^{\circledR}$ ) was provided by Roche (London, UK) and gefitinib (Iressa ${ }^{\circledR}$ ) was obtained from Astrazeneca (London, UK). For immunofluorescence assays, the monoclonal antibodies against human EGFR, HER2, HER3, and HER4 were obtained from Calbiochem (San Diego, CA, USA). The AlexaFluor 488-conjugated goat anti-mouse IgG antibody (Invitrogen, Carlsbad, CA, USA) was used as a secondary reagent. The rabbit primary antibodies for EGFR, HER2, HER3, HER4, and $\beta$-actin immunoblotting were from Santa Cruz Biotechnology (Santa Cruz, CA, USA). The mouse monoclonal antibody against phospho HER2 (Tyr1248) was from Thermo Fisher (Fremont, CA, USA). The rabbit monoclonal antibodies against phospho-Akt ${ }^{\mathrm{Ser} 473}$ and phospho HER3 and the rabbit polyclonal antibodies against Akt, ERK1/2, and phospho HER1, as well as the mouse monoclonal antibody against Phospho ERK 1/2 were all from Cell Signaling Technology (Danvers, MA, USA). The mouse monoclonal antibody against NRG-1 $\beta$ was from R\&D Systems (Minneapolis, MN, USA). The peroxidase-conjugated secondary antibodies were from Calbiochem. For neutralizing assays, a monoclonal antibody against HER3 (clone H3.105.5) was obtained from Calbiochem and the monoclonal antibody against NRG-1 (clone C-18) was from R\&D Systems.

Cell lines. The PC3 and DU145 cell lines were obtained from the American Tissue Culture Collection (Rockville, MD, USA). The cells were maintained in Dulbecco's modified Eagle's medium supplemented with $10 \%$ fetal bovine serum and $1 \%$ penicillinstreptomycin (Gibco-BRL, Grand Island, NY, USA) at $37^{\circ} \mathrm{C}$ in a humidified atmosphere containing $5 \% \mathrm{CO}_{2}$. The cells were passaged twice a week. The erlotinib DU145-resistant cell line 
(DUErR) was established by continuously exposing the cells to increasing concentrations of erlotinib. Initially the cells were treated with their corresponding inhibitory concentration 50 $\left(\mathrm{IC}_{50}\right)$ of erlotinib $(2.5 \mu \mathrm{M})$ for one month. Subsequently, the erlotinib concentration in the culture medium was increased every month to 5,10 and $15 \mu \mathrm{M}$, and then the cells were maintained in continuous culture with the maximum achieved dose of erlotinib for three additional months. Control parental cells were cultured in parallel and exposed to the phosphatebuffered saline (PBS) (Gibco-BRL) vehicle.

Growth assays. Exponentially growing cells were seeded at a density of $1.5 \times 10^{5}$ cells per dish in 100 -mm diameter dishes. The cells were allowed to attach and grow for $72 \mathrm{~h}$ in culture medium and then gefitinib $(15 \mu \mathrm{M})$, erlotinib $(15 \mu \mathrm{M})$, cetuximab $(500 \mu \mathrm{g} / \mathrm{ml})$ or a PBS vehicle alone (control cells) were added. Just before the treatments and at 24,48 and $72 \mathrm{~h}$, the cells were trypsinized and counted manually in a haemocytometer using the trypan blue dye exclusion test. Three independent counts were made from each treatment. All experiments were conducted in triplicate.

Cell proliferation assays. To assess the cytotoxicity of EGFR-inhibitors in DU145, PC3 and DUErR cells, aliquots of 4,000 cells were seeded in 96-well plates. Three days later, the cells were treated with concentrations ranging from 0 to $15 \mu \mathrm{M}$ of erlotinib, 0 to $15 \mu \mathrm{M}$ of gefitinib, and 0 to $500 \mu \mathrm{g} / \mathrm{ml}$ of cetuximab for $72 \mathrm{~h}$. Then, the treatments were removed, the cells were washed with PBS and incubated for $3 \mathrm{~h}$ with $100 \mu \mathrm{l}$ of fresh culture medium together with $10 \mu \mathrm{l}$ of MTT (3-(4,5-dimethylthiazol-2-yl)-2,5-diphenyltetrazolium bromide) (Sigma-Aldrich, St. Louis, MO, USA). The medium was discarded and dimethyl sulfoxide (DMSO) (Sigma-Aldrich) was added to each well to dissolve the purple formazan crystals. Plates were agitated at room temperature for $10 \mathrm{~min}$ and the absorbance of each well was determined with an absorbance microplate reader (ELx800, BioTek, Winooski, VT, USA) at a wavelength of $570 \mathrm{~nm}$. Three replicates were used for each experiment. The cell viability was determined as a percentage of the untreated control cells, by dividing the mean absorbance of each treatment by the mean absorbance of the untreated cells. The concentration that reduces cell viability by $50 \%\left(\mathrm{IC}_{50}\right)$ was established for gefitinib and erlotinib, while the concentration that decreases cell viability by $30 \%\left(\mathrm{IC}_{30}\right)$ was determined for cetuximab. Cell proliferation assays were also performed in order to evaluate the influence of different HER-blocking antibodies on the growth of parental DU145 cells and DUErR cell, after treating the cells for $72 \mathrm{~h}$ with either $15 \mu \mathrm{M}$ of erlotinib, $10 \mu \mathrm{g} / \mathrm{ml}$ of trastuzumab, a humanized monoclonal antibody against the extracellular domain of HER 2, $10 \mu \mathrm{g} / \mathrm{ml}$ of the anti-HER3 blocking antibody H3.105.5, $10 \mu \mathrm{g} / \mathrm{ml}$ of an anti-neuregulin-1 antibody or by different combinations of these compounds.

Quantitative real-time PCR analysis. DU145 and PC3 cells were treated for $24 \mathrm{~h}$ with a concentration analogous to the $\mathrm{IC}_{30}$ for cetuximab ( $350 \mu \mathrm{g} / \mathrm{ml}$ and $500 \mu \mathrm{g} / \mathrm{ml}$, respectively) or to the $\mathrm{IC}_{50}$ for erlotinib and gefitinib (2,5 $\mu \mathrm{M}$ and $15 \mu \mathrm{M}$, respectively) or with vehicle alone as a control. DUErR cells exposed to either erlotinib $(15 \mu \mathrm{M})$ were also analysed. The cells were washed with PBS and immediately trypsinized. The total-RNA from each sample was isolated using the RNeasy mini kit (Qiagen, Venlo, The Netherlands). The RNA concentration was measured using an ND-1000 spectrophotometer (NanoDrop Technologies, Wilmington, DE, USA) at $260 \mathrm{~nm}$, and $1 \mu \mathrm{g}$ of each RNA was reverse-transcribed into complementary DNA (cDNA) using the High Capacity cDNA Archive Kit (Applied Biosystems, Foster City, CA, USA). The expression of the HER family members EGFR, HER2, HER3, HER4, EGF, TGF- $\alpha$, AR, BTC, EPR, HB-EGF, and NRG-1 was quantified by real-time PCR using a pre-designed, gene-specific TaqMan ${ }^{\circledast}$ probe and primer sets (TaqMan ${ }^{\circledR}$ Gene Expression assays, Applied Biosystems). Quantitative PCR was performed in a standard 96-well plate format using the TaqMan One-Step Universal Master Mix (Applied Biosystems) and the 7300 Real-Time PCR system (Applied Biosystems). Cycling conditions were $95^{\circ} \mathrm{C}$ for $10 \mathrm{~min}$, followed by 40 cycles at $95^{\circ} \mathrm{C}$ for $15 \mathrm{sec}$ and $60^{\circ} \mathrm{C}$ for $1 \mathrm{~min}$. All samples were tested in triplicate. The relative quantification of the mRNA level $(\mu \mathrm{g} / \mathrm{ml})$ of HER receptors and ligands was carried out by preparing a standard curve using known dilutions of its corresponding standard RNA. Then, the mRNA level was normalized to the mRNA level of the housekeeping gene TATA box binding (TBP) protein.

Immunofluorescence analysis. The quantification of HER receptor expression on the cell membrane was performed using flow cytometry. The cells were analyzed by double immunofluorescence using monoclonal antibodies against human EGFR, HER2, HER3 and HER4 (Calbiochem). The cells were incubated for $30 \mathrm{~min}$ at $4^{\circ} \mathrm{C}$ with the primary antibody. After washing with PBS, the cells were incubated for $30 \mathrm{~min}$ at $4^{\circ} \mathrm{C}$ in the presence of the Alexa-Fluor 488-conjugated goat anti-mouse IgG antibody. Fluorescence was analyzed using a FACSCalibur flow cytometer (Becton Dickinson Immunocytometry Systems, San Jose, CA, USA) equipped with CellQuest ${ }^{\mathrm{TM}}$ software (Becton Dickinson). Fluorescence intensity was represented on a four orders of magnitude log scale $(1-10,000)$. In each experiment 10,000 cells were analyzed.

Western blot analysis. For western blot analyses, parental DU145 cells (exposed to either medium alone or supplemented with erlotinib $(2.5 \mu \mathrm{M})$ ) and DUErR cells (continuously exposed to erlotinib $(15 \mu \mathrm{M}))$ were collected and lysed with ice-cold lysis buffer containing $1 \mathrm{mM}$ EDTA, $150 \mathrm{mM} \mathrm{NaCl}, 100 \mu \mathrm{g} / \mathrm{ml}$ PMSF, $50 \mathrm{mM}$ Tris- $\mathrm{HCl}(\mathrm{pH}$ 7.5) and protease and phosphatase inhibitor cocktails (Sigma-Aldrich). Protein concentrations were determined by Lowry-based Bio-Rad assay (Bio-Rad Laboratories, Hercules, CA, USA). Equal amounts of protein extracts were electrophoresed on an 8\% SDS-PAGE gel, transferred to nitrocellulose membranes and blocked for $1 \mathrm{~h}$ at room temperature in a blocking buffer containing $2.5 \%$ powdered skim milk in PBS-T $(10 \mathrm{mM}$ Tris- $\mathrm{HCl}, \mathrm{pH} 8.0,150 \mathrm{mM} \mathrm{NaCl}$ and $0.05 \%$ Tween-20) to prevent non-specific antibody binding. Blots were incubated overnight at $4^{\circ} \mathrm{C}$ with the corresponding primary antibody diluted in blocking buffer. After washes in PBS-T, blots were incubated for $1 \mathrm{~h}$ with the corresponding secondary antibody, and revealed with a commercial kit (West Pico Chemiluminescent Substrate, Pierce Biotechnology, Rockford, IL, USA). Blots were reprobed with an antibody for $\beta$-actin to control the protein loading and transfer. 


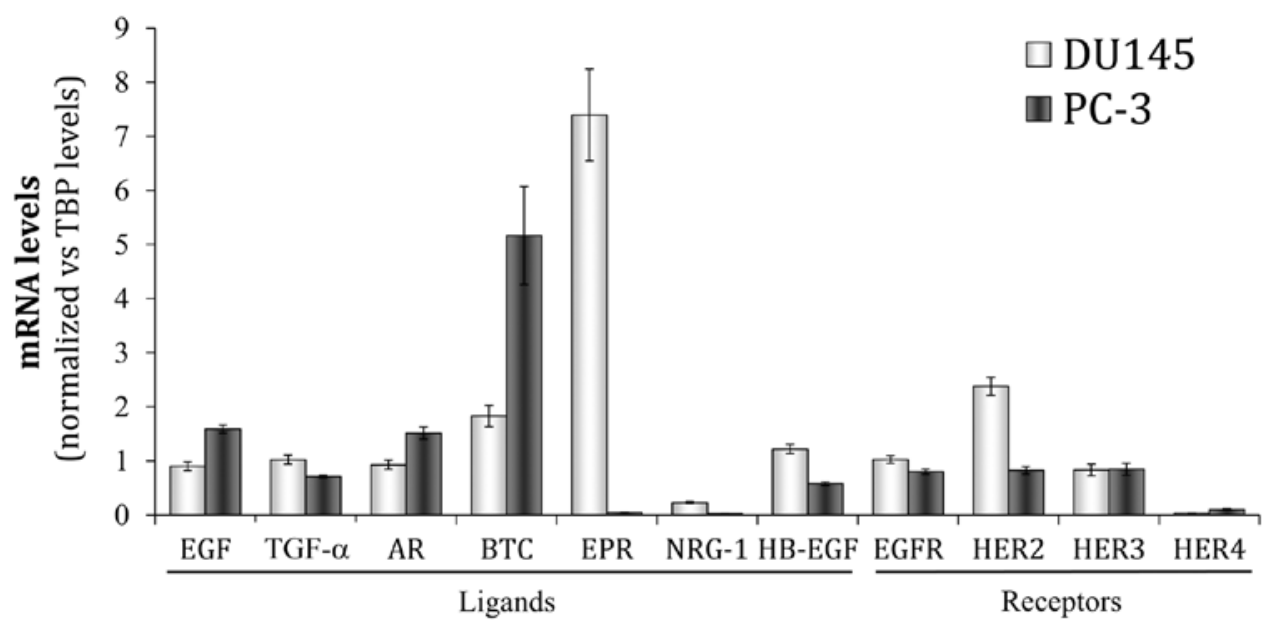

Figure 1. Gene expression pattern of HER family members in DU145 and PC3 cells. The basal mRNA level of each HER receptor (EGFR, HER2, HER3, HER4) and ligand (EGF, epidermal growth factor; TGF- $\alpha$, transforming growth factor- $\alpha$; AR, amphiregulin; BTC, betacellulin; EPR, epiregulin; NRG-1, neuregulin-1; HB-EGF, heparin-binding EGF) was assessed by real-time PCR. Each value was normalized versus the corresponding mRNA level of the TATA box binding protein (TBP) constitutive gene. The bars represent the mean value \pm SE of three independent quantifications.

Statistical analysis. The statistical analysis was performed with the SPSS statistical software for Windows (version 15.0; SPSS Inc., Chicago, IL, USA). Quantitative variables were expressed as mean and standard error (SE). The normality of the data was tested using the Kolmogorov-Smirnov test. The differences between data with normal distribution and homogeneous variances were analyzed using the parametric Student's t-test, otherwise the non-parametric Mann-Whitney U test was applied. A value of $\mathrm{P}<0.05$ was considered significant.

\section{Results}

Basal expression of HER family receptors and ligands in prostate cancer cells. The basal expression of the four HER receptors and seven different ligands (EGF, TGF- $\alpha$, AR, BTC, EREG, NRG-1 and HB-EGF) was determined according to their mRNA levels in two androgen-independent human carcinoma cell lines, DU145 and PC 3 cells, which are derived from metastases of prostate cancer, to brain and bone, respectively. Real-time PCR analyses revealed mRNA expression for the four HER receptors in both cell lines, although minimal constitutive levels of the HER4 mRNA were detected (Fig. 1). In the DU145 cells, HER2 was the receptor with the most prominent mRNA expression, followed by EGFR and HER3. EGFR, HER 2 and HER3 showed similar mRNA levels in the PC 3 cells. HER2 mRNA expression was markedly higher in the DU145 cells than in the PC3 cells, while EGFR expression was only moderately increased. The receptors expression on the cell surface was additionally analyzed by flow cytometry (Fig. 2) confirming higher protein levels of both EGFR and HER2 in the DU145 cells than in the PC 3 cells. The membrane expression of HER3 was parallel in both cell lines. In accordance with the low mRNA levels, a very weak HER4 expression on the cell surface was observed in both cell lines.

Regarding the ligands, a basal gene expression of all HER ligands analyzed was detected in both cell lines (Fig. 1). Interestingly, each cell line showed a particular expression pattern with a primarily expressed HER ligand: EPR was overexpressed in DU145 cells, while BTC was the principal ligand in PC3 cells. This is a typical feature of nearly all the epithelial cancer cells, which characteristically deregulate the expression of one or more members of the HER family (43). Notably, neuregulin-1 was the ligand with the lowest mRNA levels in both cell lines, particularly in PC3 cells.

Sensitivity of the prostate cancer cells to EGFR inhibitors. The sensitivity of the prostate cancer cells to the EGFR inhibitors was established according to the concentration of each drug required to decrease the cell viability by $50 \%\left(\mathrm{IC}_{50}\right)$ for the TKIs erlotinib and gefitinib or by $30 \%\left(\mathrm{IC}_{30}\right)$ in the case of the monoclonal antibody cetuximab, as the maximal concentration of cetuximab tested $(500 \mu \mathrm{g} / \mathrm{ml})$ did not reduce the cell viability by $50 \%$ in any cell line. As detailed in Fig. $3 \mathrm{~A}$, the $\mathrm{IC}_{50}$ values for both TKIs were around $2.5 \mu \mathrm{M}$ in DU145 cells while values were 4 to 5 -folds higher in PC3 cells. The $\mathrm{IC}_{30}$ of cetuximab was $353 \mu \mathrm{g} / \mathrm{ml}$ in DU145 and higher than $500 \mu \mathrm{g} / \mathrm{ml}$ in the PC3. According to these results, the DU145 cells were more sensitive to the three anti-EGFR agents than PC 3 cells. These observations were confirmed in the cell growth assays, where both cell lines were treated for up to $72 \mathrm{~h}$ with an elevated concentration of each compound: $15 \mu \mathrm{M}$ for erlotinib and gefitinib and $500 \mu \mathrm{g} / \mathrm{ml}$ for cetuximab. Analysis of the growth curves (Fig. 3B) showed that the proliferation rate of DU145 cells was significantly reduced by the three EGFR inhibitors. At $72 \mathrm{~h}$, the cell number was about four times lower in the erlotinib- and gefitinib-treated DU145 cells than in untreated cells, while the cetuximab effect on cell growth was more moderated. A more attenuated effect of the treatments in the PC3 cells growth was observed.

Effect of the EGFR inhibitors on the expression pattern of HER receptors and ligands. The effect of EGFR inhibitors on the endogenous expression of HER receptors and ligands was determined at the mRNA levels $24 \mathrm{~h}$ after treating the cells with a concentration analogous to the $\mathrm{IC}_{30}$ for cetuximab, to the $\mathrm{IC}_{50}$ for erlotinib and gefitinib, or with vehicle alone as a 

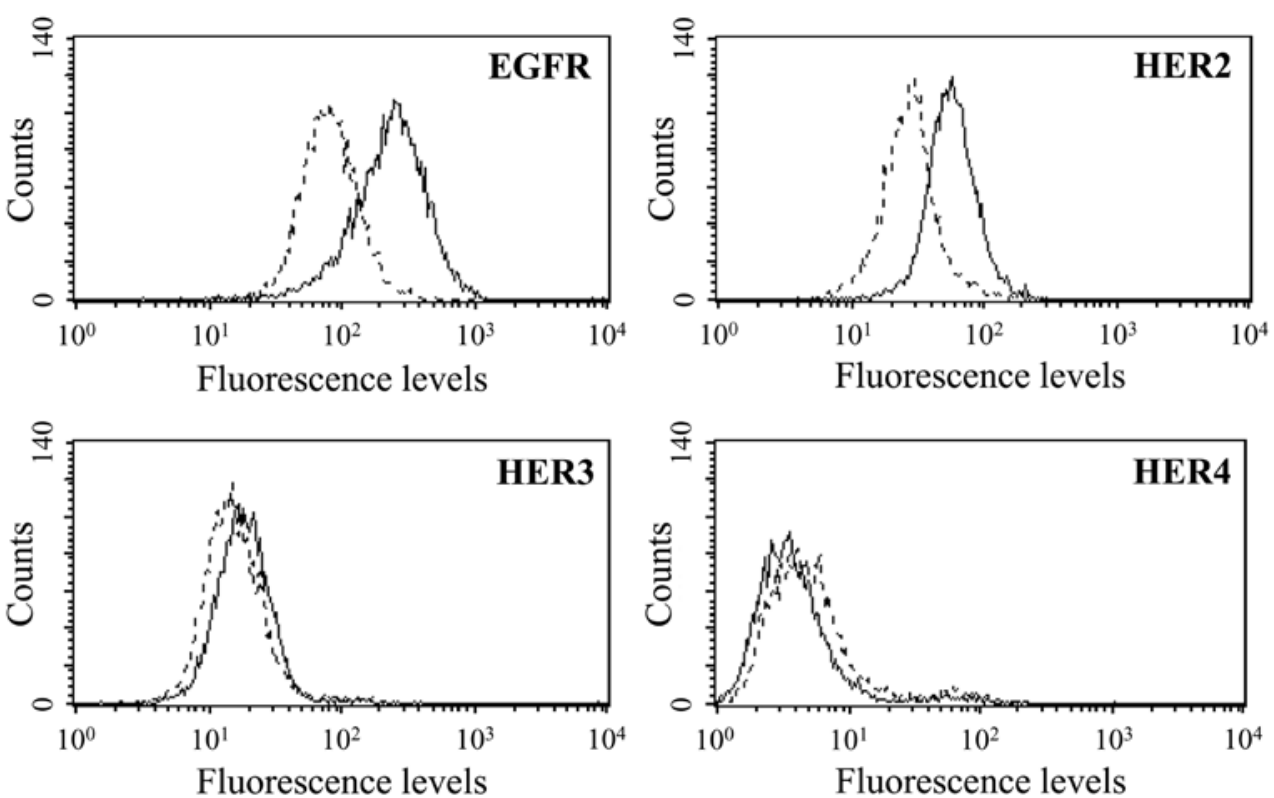

- DU145

Figure 2. Basal protein expression of HER receptors on DU145 and PC3 cells. The expression of HER receptors (EGFR, HER2, HER3 and HER4) on the cell surface was determined by flow cytometry after indirect immunofluorescence staining with the corresponding antibodies. Histograms were obtained after analyzing 10,000 cells. The fluorescence intensity is shown on a four-decade log scale. Solid lines represent DU145 cells and dashed lines PC 3 cells.

A

\begin{tabular}{ccc}
\multicolumn{3}{c}{ DU145 } \\
\hline DRUG & IC50 $(\mu \mathrm{M})$ & IC30 $(\mu \mathrm{g} / \mathrm{ml})$ \\
\hline Erlotinib & $2.47 \pm 0.43$ & \\
Gefitinib & $2.65 \pm 0.55$ & \\
Cetuximab & & $353.5 \pm 8.50$ \\
\hline
\end{tabular}

B

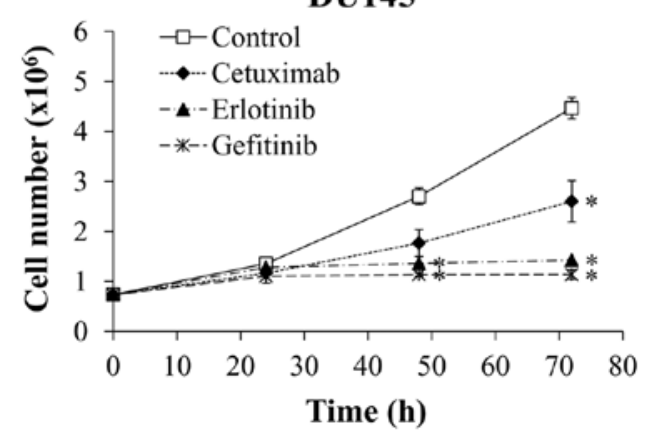

\section{PC3}

\begin{tabular}{ccc}
\hline DRUG & IC50 $(\mu \mathrm{M})$ & IC30 $(\mu \mathrm{g} / \mathrm{ml})$ \\
\hline Erlotinib & $11.53+1.87$ & \\
Gefitinib & $13.30+0.97$ & \\
Cetuximab & & $>500$ \\
\hline
\end{tabular}

PC3

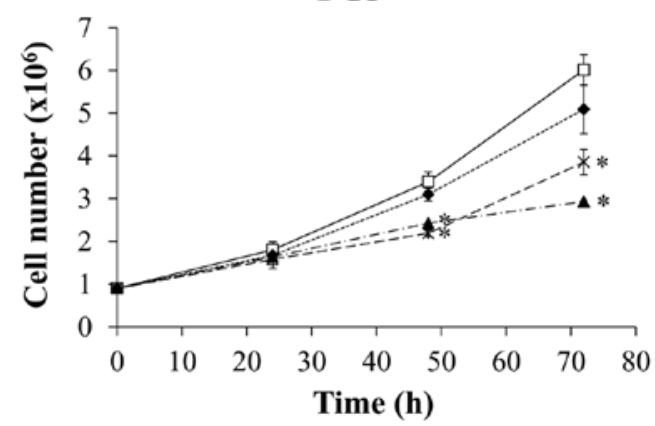

Figure 3. Sensitivity of DU145 and PC3 cells to EGFR inhibitors. (A) The concentration of cetuximab $(\mu \mathrm{g} / \mathrm{ml})$ and erlotinib/gefitinib $(\mu \mathrm{M})$, which inhibit by $30 \%\left(\mathrm{IC}_{30}\right)$ and $50 \%\left(\mathrm{IC}_{50}\right)$, respectively, the DU145 and PC3 cell viability in $72 \mathrm{~h}$, was determined using the MTT assay. Each value represents the mean \pm SE of three independent experiments. (B) Cell growth inhibition after exposing DU145 and PC3 cells to cetuximab (500 $\mu \mathrm{g} / \mathrm{ml})$, erlotinib (15 $\mu \mathrm{M})$ and gefitinib $(15 \mu \mathrm{M})$ or vehicle alone (control). The viable cell number was determined by triplicate $0,24,48$ and $72 \mathrm{~h}$ after each treatment using the trypan blue dye exclusion test. The mean value $\pm \mathrm{SE}$ of three independent experiments are represented in the graphs ( $\mathrm{P}<0.05$ vs. control cells).

control. Fig. 4 represents the variations in the gene expression compared with the corresponding untreated cells. Significant changes were observed in the DU145 cells, which overexpressed a subset of HER family members, while only minor differences were observed in the PC 3 cells. The treatment with cetuximab and the TKIs caused similar effects on each gene expression profile; although in most cases gefitinib induced the most marked changes. Remarkably, the inhibition of EGFR in the
DU145 cell line induced the mRNA overexpression of three HER ligands that display different binding affinities: EGF, BTC and NRG-1. While EGF exclusively binds EGFR, BTC is a potent survival factor that activates both EGFR and HER4 (44) and NRG-1 is a HER3 and HER4 ligand that acts as a strong mitogenic factor (45). No changes were detected in the mRNA levels of epiregulin, which is the most predominantly expressed HER ligand in DU145 cells. Along with these changes, the 

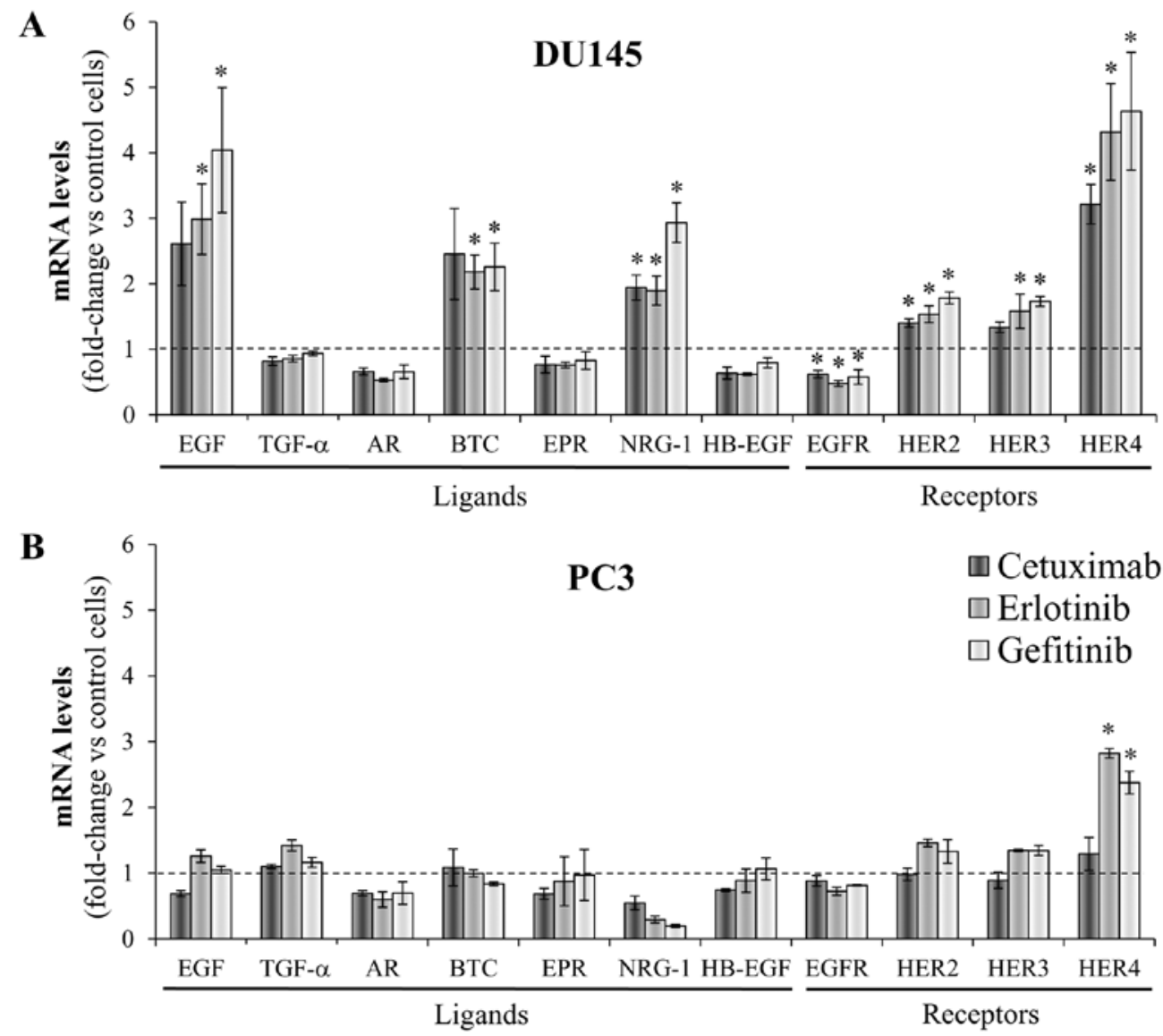

Figure 4. Changes in the gene expression of HER receptors and ligands after EGFR inhibition. (A) DU145 and (B) PC3 cells were treated with either the corresponding $\mathrm{IC}_{30}$ of cetuximab $\left(350 \mu \mathrm{g} / \mathrm{ml}\right.$ and $500 \mu \mathrm{g} / \mathrm{ml}$, respectively), the corresponding $\mathrm{IC}_{50}$ of erlotinib $(2.5 \mu \mathrm{M}$ and $15 \mu \mathrm{M}$, respectively) and gefitinib (2.5 $\mu \mathrm{M}$ and $15 \mu \mathrm{M}$, respectively) or vehicle as a control. After $24 \mathrm{~h}$, the mRNA level of each HER receptor (EGFR, HER2, HER3, HER4) and ligand (EGF, epidermal growth factor; TGF- $\alpha$, transforming growth factor- $\alpha$; AR, amphiregulin; BTC, betacellulin; EPR, epiregulin; NRG-1, neuregulin-1; HB-EGF, heparin-binding EGF) was assessed by real-time PCR in each cell line and values were normalized against the corresponding mRNA expression of the TBP constitutive gene. Then, the change in the expression of each particular gene induced by the treatments was determined by comparing the normalized values in treated cells against the corresponding normalized value in the control cells. The bars indicate the mean fold change $\pm \mathrm{SE}$ of three independent quantifications ("P $<0.05$ vs. control cells). Bars over the dotted line indicate an increase in the gene expression compared to the control cells, while bars under the dotted line represent impaired gene expression after the treatment.

mRNA level of HER2 and HER3 were moderately increased in the DU145 cells, while EGFR levels were reduced. Particularly, HER4 expression was upregulated four-fold after EGFR blockade. HER4 levels were also significantly increased but to a lesser extent, after the treatment of the PC3 cells with the TKIs.

Expression of the HER receptors and ligands in erlotinibresistant DUErR cells. In order to analyze if the overexpression of alternative HER family members might be involved in the acquired resistance to EGFR inhibitors in PCa, an erlotinibresistant DU145 cell line (DUErR) was established by exposing the cells to increasing concentrations (up to $15 \mu \mathrm{M}$ ) of erlotinib during three months followed by three additional months of cell culture in the maximal concentration of erlotinib. As represented in Fig. 5, the viability of DUErR cells was not affected by increasing concentrations of erlotinib (up to $15 \mu \mathrm{M}$ ) in the cell culture (Fig. 5A). DUErR proliferation rate was similar when the cells were cultured in the presence of erlotinib $(15 \mu \mathrm{M})$ or vehicle alone (PBS) (Fig. 5B). In contrast, the viability and proliferation of the parental DU145 cells was markedly inhibited by erlotinib. Notably, the DUErR cell line presented a slower proliferation rate compared to the parental DU145 cells (Fig. 5B). DUErR cells were also cross-resistant to gefitinib (data not shown).

Next, the mRNA expression profile of HER receptors and ligands was determined by real-time PCR in the DUErR cells and the differences from the parental control DU145 cells were assessed. As shown in Fig. 6, in erlotinib-exposed DUErR cells the NRG-1 mRNA expression was significantly amplified (more than 2-fold) and TGF- $\alpha$ expression was almost doubled compared to parental DU145 control cells. HB-EGF expression was significantly impaired in these cells. Regarding HER receptors, a 2-fold increase in HER2 and HER3 mRNA levels was detected in the erlotinib-exposed DUErR cells while slight differences in HER4 mRNA levels were observed compared with control DU145 cells. Western blot analyses confirmed an upregulation of HER 2 and HER3 protein expression in erlotinibtreated DUErR cells and a weak expression of HER4 (Fig. 7A).

HER receptors activation and downstream signaling activity in DUErR cells. The activation of EGFR, HER2, and HER3 receptors and the downstream signaling proteins, Akt and ERK1/2, was evaluated in control DU145 cells, erlotinib- 

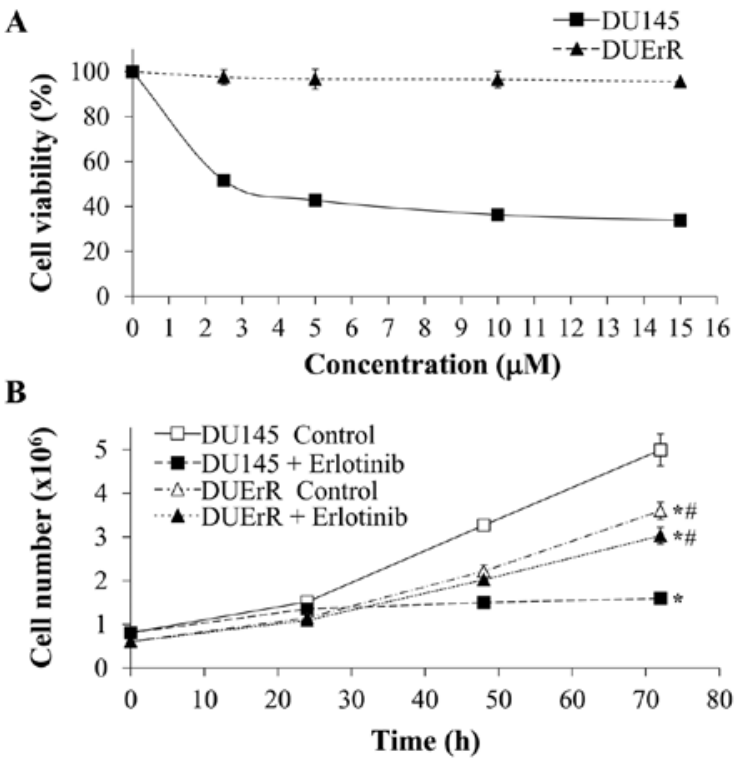

Figure 5. Growth profiles of parental DU145 cells and erlotinib-resistant cells (DUErR) exposed to erlotinib. (A) Cells were cultured in medium containing increasing concentrations of erlotinib $(0,2.5,5,10$ and $15 \mu \mathrm{M})$ for $72 \mathrm{~h}$ and the cell viability was determined by MTT assays. (B) DU145 and DUErR cells were cultured in medium alone (control) or medium containing $15 \mu \mathrm{M}$ erlotinib (+erlotinib) and the total cell number in each situation was assessed by triplicate at different time points $(0,24,48$ and $72 \mathrm{~h})$ using the trypan blue dye exclusion test. Each point in the graphs represents the mean $\pm \mathrm{SE}$ of three independent experiments. " $\mathrm{P}<0.05$ vs. control DU145 cells; ${ }^{~} \mathrm{P}<0.05$ vs. erlotinib-treated DU145 cells.

treated DU145 cells and erlotinib-exposed DUErR cells. As presented in Fig. 7A, erlotinib treatment completely abolished the phosphorylation of EGFR both in DU145 cells and in DUErR cells. In DUErR cells, together with the overexpression of HER 2 and HER3, we detected a marked increased in HER3 phosphorylation and a more attenuated activation of HER2.
HER3 overactivation was associated with enhanced levels of activated Akt in DUErR cells, while slight effects were observed in ERK1/2 phosphorylation (Fig. 7B). In contrast, after the acute treatment of DU145 cells for $72 \mathrm{~h}$ with erlotinib, the phosphorylation of HER3 was not increased compared to control cells (Fig. 7A). Thus, the signaling through the HER3/ PI3K/Akt pathway was selectively activated after the prolonged exposure of DU145 cells to erlotinib, providing a resistance mechanism to the EGFR TKI.

Effect of HER 2 and HER 3 inhibition on the proliferation of parental and erlotinib-resistant DU145 cells. In order to further determine the relative contribution of the HER receptors in the growth function of parental and erlotinib-resistant DU145 cells, both cell lines were exposed to HER2 and HER3 inactivating antibodies (trastuzumab and H3.105.5, respectively) at a dose of $10 \mu \mathrm{g} / \mathrm{ml}$ for $72 \mathrm{~h}$ (46), in presence or absence of erlotinib. As shown in Fig. 8A, the proliferation rate of both cell lines was unaffected by HER2 inhibition. Trastuzumab also failed to decrease the cell proliferation when EGFR signaling was inhibited by erlotinib (Fig. 8B). In contrast, the cell growth was significantly reduced to half when HER3 was blocked both in parental and in erlotinib resistant cell lines (Fig. 8A), revealing a key role for HER3 in mediating the proliferation of these androgen-independent prostate cells. In addition, the combination of erlotinib and the HER3 blocking antibody lead to a $25 \%$ decrease in the proliferation of parental DU145 cells compared with DU145 cells exposed to erlotinib alone. Notably, this combination resulted in a 50\% reduction in the growth of DUErR cells, restoring the cytotoxic activity of erlotinib in these cells. These results confirm a key role for HER 3 in sustaining the proliferation of prostate cells when the signaling through EGFR is inhibited. The contribution of neuregulin-1, which is a HER3 ligand, in activating the cell proliferation was also analyzed as our previous results demonstrated that both neuregulin-1 gene and protein expression was increased after the acute and

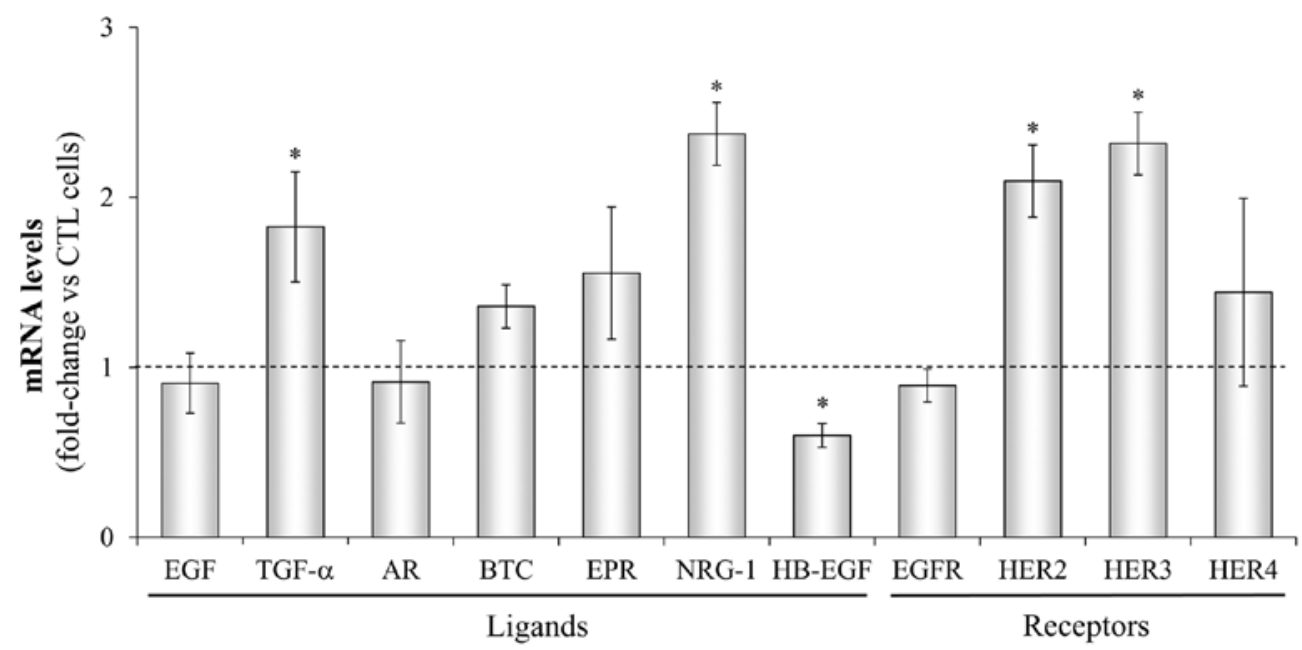

Figure 6. Changes in the gene expression of HER receptors and ligands in DUErR cells. The gene expression of each HER receptor (EGFR, HER2, HER3, HER4) and ligand (EGF, epidermal growth factor; TGF- $\alpha$, transforming growth factor- $\alpha$; AR, amphiregulin; BTC, betacellulin; EPR, epiregulin; NRG, neuregulin; HB-EGF, heparin-binding EGF) was determined by real-time PCR in parental DU145 cells (control) and in erlotinib-resistant DUErR cells (cultured in medium containing $15 \mu \mathrm{M}$ erlotinib). Each value was normalized against the corresponding mRNA level of the TBP constitutive gene. Then, the change in the expression of each particular gene was assessed in DUErR cells compared to the control cells. The bars represent the mean fold-change \pm SE of three independent quantifications $\left({ }^{*} \mathrm{P}<0.05\right.$ vs. control cells). Bars over the dotted line indicate an increase in the gene expression compared to the control cells, while bars under the line represent impaired gene expression after the treatment. 


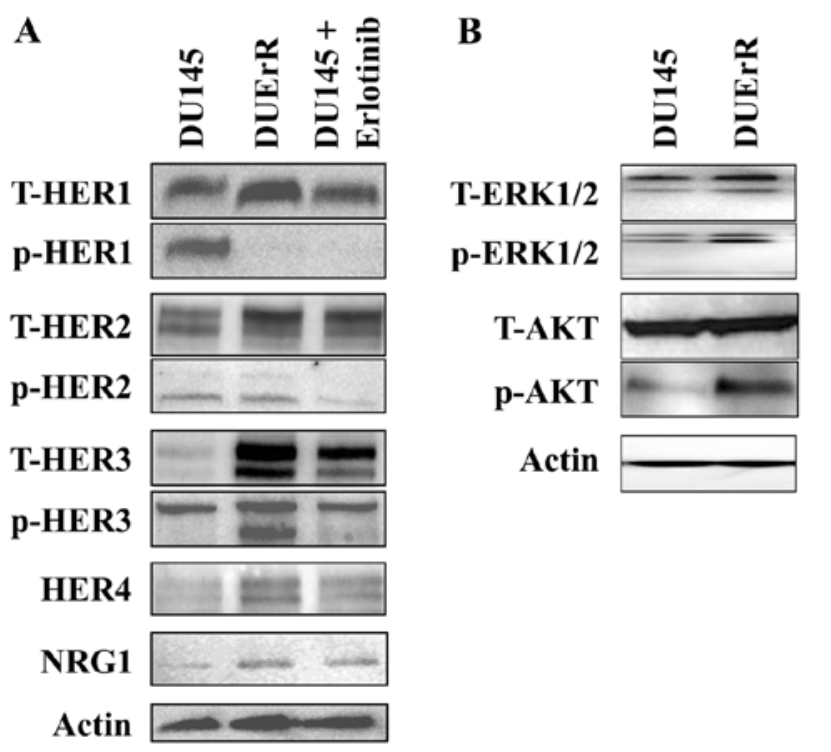

Figure 7. HER receptors activation and downstream signaling in control, erlotinib-treated and erlotinib-resistant DU145 cells. (A) Equal amounts of protein lysates from parental DU145 cells [exposed to either medium alone (control) or supplemented with erlotinib $(2.5 \mu \mathrm{M})]$ and erlotinib-resistant (DUErR) cells [continuously exposed to erlotinib $(15 \mu \mathrm{M})$ ] were immunoblotted with anti-EGFR, anti-HER2, anti-HER3, anti-HER4 and anti-neuregulin-1 (NRG1) antibodies to determine the protein levels. Receptor activation was analyzed by assessing their phosphorylation status using the corresponding phosphospecific antibody. (B) Total and phosphorylated levels of the ERK1/2 and AKT signaling proteins were specifically determined in control DU145 cells and erlotinib-exposed DUErR cells. Actin levels were used as loading control.

prolonged exposure of DU145 cells to erlotinib. However, after incubating the cells with an antibody against neuregulin-1, we observed a very moderate reduction on cell proliferation. These results suggest a relative role for neuregulin-1 in promoting the cell survival, probably because other ligands, like neuregulin-2, may be involved in activating the signaling through HER3 in these cells. In addition, a recent work describe that HER3 may be activated in a neuregulin-1 independent manner in DU145 cells (22).

\section{Discussion}

EGFR expression is involved in PCa progression and correlates with androgen independence and metastasis of prostate cancer cells $(3,4,47)$. However, the results of clinical trials involving EGFR inhibitors have revealed a reduced efficacy in PCa patients (27-29,35). The cooperative nature of the HER family might play an important role in the low effectiveness of drugs targeting EGFR as the co-expression of different HER members in the cancer cell can activate parallel signaling pathways to circumvent the inhibition of this specific receptor $(6,48)$. Actually, analysis of clinical data has revealed that patients overexpressing two or more HER family members develop more aggressive malignancies than patients that overexpress a single receptor (49-52).

In the present study, we were interested in determining if the endogenous expression of alternative HER family members might contribute to the inefficacy of EGFR inhibitors in PCa cells. To this end, the expression pattern of EGFR, HER2, HER3, and

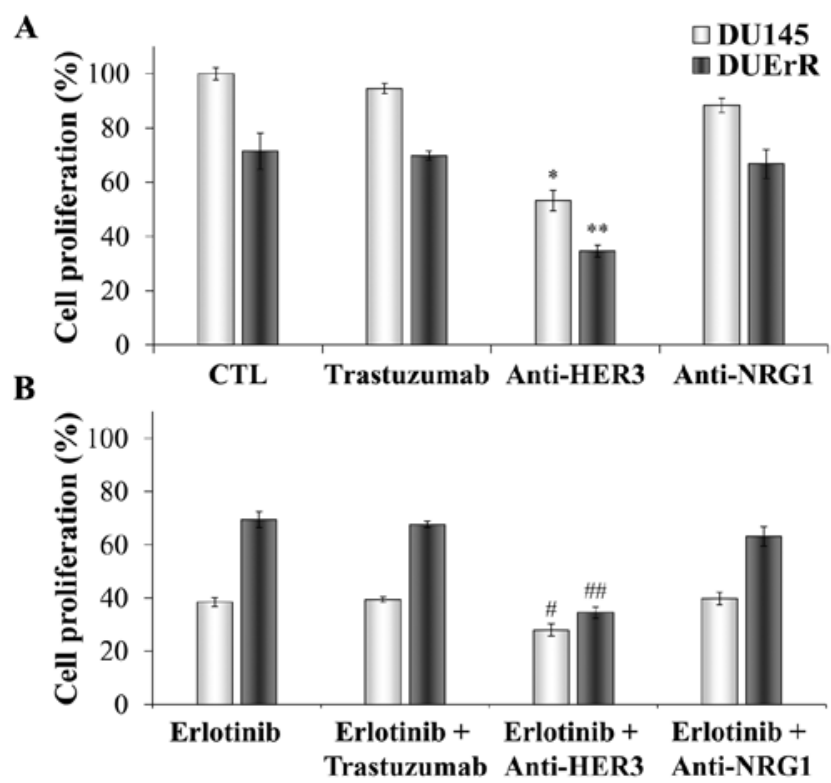

Figure 8. Effect of EGFR, HER2 and HER3 inhibition on the proliferation of parental and erlotinib-resistant DU145 cells. DU145 and DUErR cells were exposed for $72 \mathrm{~h}$ to antibodies directed at either HER2 (trastuzumab), HER3 (anti-HER3) or neuregulin (anti-NRG1) alone (A) or combined with erlotinib $(15 \mu \mathrm{M})(\mathrm{B})$ and the relative cell proliferation versus untreated (control) DU145 cells was assessed. Each column in the graph represents the mean \pm SE of three independent experiments. * $\mathrm{P}<0.05$ vs. DU145 control cells; ${ }^{* *} \mathrm{P}<0.05$ vs. DUErR control cells; ${ }^{*} \mathrm{P}<0.05$ vs. erlotinib-treated DU145 cells; ${ }^{\# \#} \mathrm{P}<0.05$ vs. erlotinib-treated DUErR cells.

HER4 as well as seven ligands of the HER family was assessed in the DU145 and PC3 androgen-independent human prostate carcinoma cell lines at basal level and after the treatment with the EGFR-directed antibody cetuximab and the EGFR TKIs gefitinib and erlotinib. Both cell lines are EGFR-positive, however PC3 cells lack the phosphatase and tensin homolog tumor (PTEN) gene expression, which is a tumor suppressor protein that down-regulates the PI3K/Akt pathway. The loss of PTEN results in a continuous signaling though the PI3K/Akt pathway independently of the upstream receptor activation (53-55). The absence of the PTEN gene is a common feature of PCa, as about $50 \%$ of prostate tumors lack PTEN expression (56). Our results showed that the sensitivity to EGFR inhibitors, determined as $\mathrm{IC}_{50}$ or $\mathrm{IC}_{30}$ values as well as the inhibition of the cell growth, was markedly higher in the PTEN-positive DU145 cells than in the PC3 cells. These results are in agreement with a previous study, where the sensitivity against erlotinib was strongly dependent on PTEN presence in PCa cells (26). In that study, the efficacy of erlotinib was inversely related to the EGFR/HER2 ratio; however, we did not find this association. Our data indicate a direct association between EGFR expression levels and the effectiveness of the treatments.

Our findings have demonstrated the constitutive co-expression of different HER receptors and ligands at the mRNA level in both PCa cell lines. The expression profile of the HER ligands was cell type-specific. Epiregulin was the predominant ligand in DU145 cells while betacellulin was the main ligand in PC3 cells. Both are EGFR ligands, which is the most largely expressed receptor at protein level in both cell lines. Thus, 
tumor cell proliferation could be sustained autonomously by the autocrine production of growth factors. In fact, both cell lines were able to proliferate independently of the exogenous supply of growth factors in the cell culture (data not shown). Highly increased expression of epiregulin and amphiregulin, together with TGF- $\alpha$ and HB-EGF, has been previously described in androgen-independent prostate cancer compared to normal prostate epithelial cells or androgen-sensitive cancer cells $(57,58)$. Epiregulin and amphiregulin expression also increased after androgen deprivation in an androgen-sensitive prostate cancer xenograft, indicating that these growth factors might contribute to the tumor progression to an androgenindependent stage (59). In addition, the expression of epiregulin in breast cancer cells together with further three genes was identified as a key determinant for pulmonary metastasis (60). Epiregulin and amphiregulin gene expression has also been associated with the development of liver metastasis in colorectal cancer patients (61). Our group and others have recently reported that an elevated gene expression of epiregulin and amphiregulin in cancer cells might be a predictive marker of the therapeutic response to cetuximab $(62,63)$. In keeping with this observation, the epiregulin-overexpressing DU145 cells were markedly more sensitive to cetuximab than the PC3 cell line.

In response to inhibition of EGFR signaling by cetuximab, gefitinib and erlotinib treatments, the gene expression of EGF, betacellulin and neuregulin ligands along with the HER2, HER3 and HER4 receptors was significantly increased in the DU145 cells. Interestingly, the alternative binding affinities of these ligands might activate all possible HER heterodimers to compensate the loss of EGFR function and preserve the EGFR downstream cell signaling. In contrast, slight differences in the mRNA levels of HER family members were observed in the PC3 cell line, which only upregulated HER4 expression, indicating that the autocrine growth factor loops are attenuated when the signaling activity through the EGFR pathways is constitutively activated independently of ligand binding. While the upregulation of HER2 and HER3 was moderate in DU145 cells, the mRNA levels of HER4 were increased by four times after EGFR inhibition. A few studies have analyzed the role of HER4 receptor in $\mathrm{PCa}$, and the conclusions are controversial. Some investigators have correlated the expression of HER4 with enhanced prostate cell proliferation and migratory capacity $(64,65)$, but others have reported that HER4 has a tumor-suppressive effect $(66,67)$. HER4 activity has also been related to acquired resistance to anti-EGFR therapies, as the signaling through the PI3K/Akt survival pathway can be alternatively activated by HER4 (39). Although we have observed a marked increase in HER4 mRNA levels shortly after EGFR inhibition, the low protein expression of HER4 in DU145 cells suggest a reduced contribution of this receptor to overcome EGFR blockade.

There is growing evidence that tumor cells might circumvent the effects of EGFR inhibitors through the promotion of HER3/HER2 heterodimerization and the activation of the PI3K/Akt pathway $(38,45,61,68-70)$. Our results confirm the relevance of HER3 in mediating resistance to EGFR TKIs in androgen-independent prostate cancer cells. The erlotinibresistant (DUErR) cells, as well as the parental DU145 cells, showed a strong dependence on HER3 for proliferation, as HER3 neutralization lead to a significant reduction in the growth of both cell lines. The prolonged exposure of DU145 cells to erlotinib induced a reprogramming of HER family members expression and HER2 and HER3 levels were significantly upregulated, along with neuregulin-1, which is a HER3 natural ligand, and TGF- $\alpha$, which exclusively binds EGFR. Ligand-activated HER3 might be then transactivated by heterodimerization with HER2, or even with relatively low levels of active EGFR, leading to an enhanced activity through the PI3K/Akt survival pathway and, thus providing a plausible escape mechanism to the EGFR blockade. Importantly, HER3 inhibition rendered the DUErR cells sensitive to erlotinib, indicating a key role for this receptor in driving the resistance to EGFR-targeted therapies in PCa cells.

HER ligands have also been considered as targets for cancer therapy, as the loss of HER receptors function can be balanced by the endogenous expression of their cognate ligands by cancer cells. However the redundancy of ligands for each receptor may limit the effectiveness of this strategy, leading to a general consensus that inhibiting the receptor function is more effective than inhibiting multiple ligands. Our results are in keeping with this hypothesis, as the proliferation of the cells was prominently reduced after blocking the HER3 receptor, while targeting a particular ligand, neuregulin-1, revealed a minor effectiveness in reducing the cell growth.

In conclusion, our results show the ability of the androgenindependent PCa cells to rapidly modulate the expression of HER receptors and ligands to sustain the cell proliferation after EGFR blockage and a central role for HER3 in mediating resistance to EGFR inhibition. This molecular mechanism might be especially relevant in the physiological conditions, as the proliferation of malignant prostate cells is markedly dependent on the autocrine release of growth factors as well as the expression of their corresponding receptors in the tumor microenvironment. Therefore, the clinical efficacy of the current therapeutic approaches targeting EGFR in prostate cancer might be improved by the dual inhibition of EGFR and HER3 receptors.

\section{Acknowledgements}

We acknowledge the Instituto de Salud Carlos III (grants RD06/0020/0041, RD06/0020/0028), Universitat de Girona (grant PUG2007A/10) and Generalitat de Catalunya (grant 2009SGR208) for providing funding for this project. D.C.S. and C.P. acknowledge their fellowships from Ministerio de Educación y Ciencia (grant AP2007-01953) and Universitat de Girona (grant BR08/19), respectively.

\section{References}

1. Zhu ML and Kyprianou N: Androgen receptor and growth factor signaling cross-talk in prostate cancer cells. Endocr Relat Cancer 15: 841-849, 2008.

2. Pomerantz $M$ and Kantoff P: Advances in the treatment of prostate cancer. Annu Rev Med 58: 205-220, 2007.

3. Traish AM and Morgentaler A: Epidermal growth factor receptor expression escapes androgen regulation in prostate cancer: a potential molecular switch for tumour growth. Br J Cancer 101: 1949-1956, 2009.

4. Shah RB, Ghosh D and Elder JT: Epidermal growth factor receptor (ErbB1) expression in prostate cancer progression: correlation with androgen independence. Prostate 66: 1437-1444, 2006.

5. Yarden Y and Sliwkowski MX: Untangling the ErbB signalling network. Nat Rev Mol Cell Biol 2: 127-137, 2001. 
6. Normanno N, De Luca A, Bianco C, et al: Epidermal growth factor receptor (EGFR) signaling in cancer. Gene 366: 2-16, 2006.

7. Shi F, Telesco SE, Liu Y, Radhakrishnan R and Lemmon MA: ErbB3/HER3 intracellular domain is competent to bind ATP and catalyze autophosphorylation. Proc Natl Acad Sci USA 107: 7692-7697, 2010

8. Pinkas-Kramarski R, Shelly M, Glathe S, Ratzkin BJ and Yarden Y: Neu differentiation factor/neuregulin isoforms activate distinct receptor combinations. J Biol Chem 271: 19029-19032, 1996.

9. Wilson KJ, Gilmore JL, Foley J, Lemmon MA and Riese DJ II: Functional selectivity of EGF family peptide growth factors: implications for cancer. Pharmacol Ther 122: 1-8, 2009.

10. Iwamoto R, Yamazaki S, Asakura M, et al: Heparin-binding EGF-like growth factor and ErbB signaling is essential for heart function. Proc Natl Acad Sci USA 100: 3221-3226, 2003.

11. Miyamoto S, Fukami T, Yagi H, Kuroki M and Yotsumoto F: Potential for molecularly targeted therapy against epidermal growth factor receptor ligands. Anticancer Res 29: 823-830, 2009.

12. Hynes NE and Lane HA: ERBB receptors and cancer: the complexity of targeted inhibitors. Nat Rev Cancer 5: 341-354, 2005 .

13. Salomon DS, Brandt R, Ciardiello F and Normanno N: Epidermal growth factor-related peptides and their receptors in human malignancies. Crit Rev Oncol Hematol 19: 183-232, 1995.

14. Normanno N, Bianco C, De Luca A, Maiello MR and Salomon DS: Target-based agents against ErbB receptors and their ligands: a novel approach to cancer treatment. Endocr Relat Cancer 10: 1-21, 2003.

15. Scaltriti $\mathrm{M}$ and Baselga J: The epidermal growth factor receptor pathway: a model for targeted therapy. Clin Cancer Res 12: 5268-5272, 2006.

16. Baselga $\mathrm{J}$ : Targeting tyrosine kinases in cancer: the second wave. Science 312: 1175-1178, 2006.

17. Bianco R, Troiani $\mathrm{T}$, Tortora $\mathrm{G}$ and Ciardiello F: Intrinsic and acquired resistance to EGFR inhibitors in human cance therapy. Endocr Relat Cancer 12 (Suppl 1): S159-S171, 2005.

18. Marshall J: Clinical implications of the mechanism of epidermal growth factor receptor inhibitors. Cancer 107: 1207-1218, 2006

19. Benavente S, Huang S, Armstrong EA, et al: Establishment and characterization of a model of acquired resistance to epidermal growth factor receptor targeting agents in human cancer cells. Clin Cancer Res 15: 1585-1592, 2009.

20. Di Lorenzo G, Tortora G, D'Armiento FP, et al: Expression of epidermal growth factor receptor correlates with disease relapse and progression to androgen-independence in human prostate cancer. Clin Cancer Res 8: 3438-3444, 2002.

21. Craft N, Shostak Y, Carey M and Sawyers CL: A mechanism for hormone-independent prostate cancer through modulation of androgen receptor signaling by the HER-2/neu tyrosine kinase. Nat Med 5: 280-285, 1999.

22. Soler M, Mancini F, Meca-Cortes O, et al: HER3 is required for the maintenance of neuregulin-dependent and -independent attributes of malignant progression in prostate cancer cells. Int J Cancer 125: 2565-2575, 2009.

23. Ricciardelli C, Jackson MW, Choong CS, et al: Elevated levels of HER-2/neu and androgen receptor in clinically localized prostate cancer identifies metastatic potential. Prostate 68: 830-838, 2008.

24. Vicentini C, Festuccia C, Gravina GL, Angelucci A, Marronaro A and Bologna M: Prostate cancer cell proliferation is strongly reduced by the epidermal growth factor receptor tyrosine kinase inhibitor ZD1839 in vitro on human cell lines and primary cultures. J Cancer Res Clin Oncol 129: 165-174, 2003.

25. Dhupkar P, Dowling M, Cengel K and Chen B: Effects of anti-EGFR antibody cetuximab on androgen-independent prostate cancer cells. Anticancer Res 30: 1905-1910, 2010.

26. Festuccia C, Gravina GL, Biordi L, et al: Effects of EGFR tyrosine kinase inhibitor erlotinib in prostate cancer cells in vitro. Prostate 69: 1529-1537, 2009.

27. Canil CM, Moore MJ, Winquist E, et al: Randomized phase II study of two doses of gefitinib in hormone-refractory prostate cancer: a trial of the National Cancer Institute of Canada-Clinical Trials Group. J Clin Oncol 23: 455-460, 2005.

28. Gravis G, Bladou F, Salem N, et al: Results from a monocentric phase II trial of erlotinib in patients with metastatic prostate cancer. Ann Oncol 19: 1624-1628, 2008.
29. Wilding G, Soulie P, Trump D, Das-Gupta A and Small E: Results from a pilot phase I trial of gefitinib combined with docetaxel and estramustine in patients with hormone-refractory prostate cancer. Cancer 106: 1917-1924, 2006.

30. Ziada A, Barqawi A, Glode LM, et al: The use of trastuzumab in the treatment of hormone refractory prostate cancer; phase II trial. Prostate 60: 332-337, 2004

31. Whang YE, Armstrong AJ, Rathmell WK, et al: A phase II study of lapatinib, a dual EGFR and HER-2 tyrosine kinase inhibitor, in patients with castration-resistant prostate cancer. Urol Oncol: Mar 9, 2011 (Epub ahead of print).

32. Sridhar SS, Hotte SJ, Chin JL, et al: A multicenter phase II clinical trial of lapatinib (GW572016) in hormonally untreated advanced prostate cancer. Am J Clin Oncol 33 : 609-613, 2010.

33. Nabhan C, Lestingi TM, Galvez A, et al: Erlotinib has moderate single-agent activity in chemotherapy-naive castration-resistant prostate cancer: final results of a phase II trial. Urology 74: 665-671, 2009.

34. Yotsumoto F, Yagi H, Suzuki SO, et al: Validation of HB-EGF and amphiregulin as targets for human cancer therapy. Biochem Biophys Res Commun 365: 555-561, 2008.

35. Ferrer-Soler L, Vazquez-Martin A, Brunet J, Menendez JA, De Llorens R and Colomer R: An update of the mechanisms of resistance to EGFR-tyrosine kinase inhibitors in breast cancer: gefitinib (Iressa) -induced changes in the expression and nucleo-cytoplasmic trafficking of HER-ligands (Review). Int J Mol Med 20: 3-10, 2007.

36. Li C, Iida M, Dunn EF, Ghia AJ and Wheeler DL: Nuclear EGFR contributes to acquired resistance to cetuximab. Oncogene 28: 3801-3813, 2009.

37. Ritter CA, Perez-Torres M, Rinehart C, et al: Human breast cancer cells selected for resistance to trastuzumab in vivo overexpress epidermal growth factor receptor and ErbB ligands and remain dependent on the ErbB receptor network. Clin Cancer Res 13: 4909-4919, 2007.

38. Hutcheson IR, Knowlden JM, Hiscox SE, et al: Heregulin beta1 drives gefitinib-resistant growth and invasion in tamoxifenresistant MCF-7 breast cancer cells. Breast Cancer Res 9: R50, 2007.

39. Kong A, Calleja V, Leboucher P, Harris A, Parker PJ and Larijani B: HER2 oncogenic function escapes EGFR tyrosine kinase inhibitors via activation of alternative HER receptors in breast cancer cells. PLoS One 3: e2881, 2008.

40. Amin DN, Campbell MR and Moasser MM: The role of HER3, the unpretentious member of the HER family, in cancer biology and cancer therapeutics. Semin Cell Dev Biol 21: 944-950, 2010.

41. Baselga $J$ and Swain SM: Novel anticancer targets: revisiting ERBB2 and discovering ERBB3. Nat Rev Cancer 9: 463-475, 2009.

42. Sergina NV, Rausch M, Wang D, et al: Escape from HER-family tyrosine kinase inhibitor therapy by the kinase-inactive HER3. Nature 445: 437-441, 2007.

43. Mendelsohn J: Antibody-mediated EGF receptor blockade as an anticancer therapy: from the laboratory to the clinic. Cancer Immunol Immunother 52: 342-346, 2003.

44. Pinkas-Kramarski R, Lenferink AE, Bacus SS, et al: The oncogenic ErbB-2/ErbB-3 heterodimer is a surrogate receptor of the epidermal growth factor and betacellulin. Oncogene 16: 1249-1258, 1998

45. Montero JC, Rodriguez-Barrueco R, Ocana A, Diaz-RodriguezE, Esparis-Ogando A and Pandiella A: Neuregulins and cancer. Clin Cancer Res 14: 3237-3241, 2008.

46. Dua R, Zhang J, Nhonthachit P, Penuel E, Petropoulos C and Parry G: EGFR over-expression and activation in high HER2, ER negative breast cancer cell line induces trastuzumab resistance. Breast Cancer Res Treat 122: 685-697, 2010.

47. Festuccia C, Angelucci A, Gravina GL, et al: Epidermal growth factor modulates prostate cancer cell invasiveness regulating urokinase-type plasminogen activator activity. EGF-receptor inhibition may prevent tumor cell dissemination. Thromb Haemost 93: 964-975, 2005.

48. Viloria-Petit AM and Kerbel RS: Acquired resistance to EGFR inhibitors: mechanisms and prevention strategies. Int J Radiat Oncol Biol Phys 58: 914-926, 2004.

49. Koutsopoulos AV, Mavroudis D, Dambaki KI, et al: Simultaneous expression of c-erbB-1, c-erbB-2, c-erbB-3 and c-erbB-4 receptors in non-small-cell lung carcinomas: correlation with clinical outcome. Lung Cancer 57: 193-200, 2007. 
50. Onn A, Correa AM, Gilcrease M, et al: Synchronous overexpression of epidermal growth factor receptor and HER2-neu protein is a predictor of poor outcome in patients with stage I non-small cell lung cancer. Clin Cancer Res 10: 136-143, 2004.

51. Chow NH, Chan SH, Tzai TS, Ho CL and Liu HS: Expression profiles of ErbB family receptors and prognosis in primary transitional cell carcinoma of the urinary bladder. Clin Cancer Res 7: 1957-1962, 2001

52. Wiseman SM, Makretsov N, Nielsen TO, et al: Coexpression of the type 1 growth factor receptor family members HER-1, HER-2, and HER-3 has a synergistic negative prognostic effect on breast carcinoma survival. Cancer 103: 1770-1777, 2005.

53. Brader S and Eccles SA: Phosphoinositide 3-kinase signalling pathways in tumor progression, invasion and angiogenesis. Tumori 90: 2-8, 2004.

54. Festuccia C, Muzi P, Millimaggi D, et al: Molecular aspects of gefitinib antiproliferative and pro-apoptotic effects in PTENpositive and PTEN-negative prostate cancer cell lines. Endocr Relat Cancer 12: 983-998, 2005.

55. Wang G, Reed E and Li QQ: Apoptosis in prostate cancer: progressive and therapeutic implications (Review). Int J Mol Med 14: 23-34, 2004.

56. Vlietstra RJ, van Alewijk DC, Hermans KG, van Steenbrugge GJ and Trapman J: Frequent inactivation of PTEN in prostate cancer cell lines and xenografts. Cancer Res 58: 2720-2723, 1998.

57. Zhu Z, Kleeff J, Friess H, et al: Epiregulin is Up-regulated in pancreatic cancer and stimulates pancreatic cancer cell growth. Biochem Biophys Res Commun 273: 1019-1024, 2000.

58. Torring N, Jorgensen PE, Sorensen BS and Nexo E: Increased expression of heparin binding EGF (HB-EGF), amphiregulin, TGF alpha and epiregulin in androgen-independent prostate cancer cell lines. Anticancer Res 20: 91-95, 2000.

59. Torring N, Hansen FD, Sorensen BS, Orntoft TF and Nexo E: Increase in amphiregulin and epiregulin in prostate cancer xenograft after androgen deprivation-impact of specific HER1 inhibition. Prostate 64: 1-8, 2005.

60. Gupta GP, Nguyen DX, Chiang AC, et al: Mediators of vascular remodelling co-opted for sequential steps in lung metastasis. Nature 446: 765-770, 2007
61. Watanabe T, Kobunai T, Yamamoto Y, et al: Prediction of liver metastasis after colorectal cancer using reverse transcriptionpolymerase chain reaction analysis of 10 genes. Eur J Cancer 46: 2119-2126, 2010

62. Oliveras-Ferraros C, Vall-Llovera AM, Salip DC, et al: Evolution of the predictive markers amphiregulin and epiregulin mRNAs during long-term cetuximab treatment of KRAS wild-type tumor cells. Invest New Drugs 30: 846-852, 2012.

63. Baker JB, Dutta D, Watson D, et al: Tumour gene expression predicts response to cetuximab in patients with KR AS wild-type metastatic colorectal cancer. Br J Cancer 104: 488-495, 2011.

64. Ben-Yosef R, Starr A, Karaush V, et al: ErbB-4 may control behavior of prostate cancer cells and serve as a target for molecular therapy. Prostate 67: 871-880, 2007.

65. Vexler A, Lidawi G, Loew V, et al: Anti-ERBb4 targeted therapy combined with radiation therapy in prostate cancer. Results of in vitro and in vivo studies. Cancer Biol Ther 7: 1090-1094, 2008.

66. Edwards J, Traynor P, Munro AF, Pirret CF, Dunne B and Bartlett JM: The role of HER1-HER4 and EGFRvIII in hormonerefractory prostate cancer. Clin Cancer Res 12: 123-130, 2006.

67. Center MM, Jemal A, Smith RA and Ward E: Worldwide variations in colorectal cancer. CA Cancer J Clin 59: 366-378, 2009.

68. De Alava E, Ocana A, Abad M, et al: Neuregulin expression modulates clinical response to trastuzumab in patients with metastatic breast cancer. J Clin Oncol 25: 2656-2663, 2007.

69. Motoyama AB, Hynes NE and Lane HA: The efficacy of ErbB receptor-targeted anticancer therapeutics is influenced by the availability of epidermal growth factor-related peptides. Cancer Res 62: 3151-3158, 2002.

70. Normanno N, De Luca A, Maiello MR, et al: The MEK/MAPK pathway is involved in the resistance of breast cancer cells to the EGFR tyrosine kinase inhibitor gefitinib. J Cell Physiol 207: 420-427, 2006 